\begin{tabular}{|c|l|}
\hline Title & Biological origin for amino acids in a deep subterranean hydrothermal vent, Toy oha mine, Hokkaido, Japan \\
\hline Author(s) & Takano, Yoshinori; Sato, Ryotaro; Kaneko, Takeo; Kobay ashi, Kensei; Marumo, Katsumi \\
\hline Citation & $\begin{array}{l}\text { Organic Geochemistry, 34(11), 1491-1496 } \\
\text { https://doi.org/10.1016/S0146-6380(03)00175-X }\end{array}$ \\
\hline Issue Date & 2003-11 \\
\hline Doc URL & http://hdl.handle.net/2115/48277 \\
\hline Type & article(author version) \\
\hline File Information & Takano_HUSCAP_0G2003.pdf \\
\hline
\end{tabular}

Instructions for use 


\title{
Biological origin for amino acids in a deep subterranean hydrothermal vent, Toyoha mine, Hokkaido, Japan.
}

\author{
Yoshinori Takano ${ }^{1,2}$, Ryotaro Sato ${ }^{1}$, Takeo Kaneko ${ }^{1}$,
} Kensei Kobayashi ${ }^{1}$ and Katsumi Marumo ${ }^{2}$

${ }^{1}$ Department of Chemistry and Biotechnology, Yokohama National University, 79-5 Hodogaya, Yokohama 240-8501, Japan

${ }^{2}$ Institute for Marine Resources and Environment, National Institute for Advanced Industrial Science and Technology (AIST) AIST Central 7, 1-1-1 Higashi, Tsukuba, Ibaraki 305-8567, Japan

Abstract- Concentration of amino acids were determined for the investigation of subterranean microbiological activities in geothermal environments at Toyoha Mines,

15 Hokkaido, Japan. Samples used were three specimens collected in hydrothermal water, and boring cores from a hydrothermal vein and a quartz vein. Total hydrolyzed amino acids (THAA) in the hydrothermal water were in the range of $2.5 \mu \mathrm{mol} / 1$ and $6.2 \mu \mathrm{mol} / 1$. $\mathrm{D} / \mathrm{L}$ ratios of aspartic acid, glutamic acid and alanine of the three samples were quite low, which was not more than 0.16. THAA in the hydrothermal vein rock and the

20 quartz vein rock were $0.2 \mu \mathrm{mol} / \mathrm{g}$-rock and $0.1 \mu \mathrm{mol} / \mathrm{g}$-rock, respectively. $\mathrm{D} / \mathrm{L}$ ratios of samples imply those amino acids were generated through microbiological activities, not abiotic hydrothermal chemical synthesis.

Keywords - amino acids, D/L ratio, hydrothermal environment, deep subterranean 25 biosphere 
Takano et al., Organic Geochemistry, 34, 1491-1496 (2003).

\section{INTRODUCTION}

The deep subsurface is one of the major habitats for microorganisms (Gold, 1992). Subterranean microorganisms are recently detected in the course of ocean drilling experiments (Parkes et al., 1994; Craggs et al., 1994). These microbial populations

30 are substantial (e.g. $10^{7}$ cells $/ \mathrm{cm}^{3}$ at $500 \mathrm{~m}$ below sea floor) and likely to be widespread below sea floor. In order to evaluate microbial activities in extreme environments, several analytical chemical approaches have been proposed. Amino acids are common components of all organisms and constitute a major fraction of organic compounds in subsurface. Thus amino acid analysis is one of the most promising

35 chemical techniques to search for the subterranean microbial activities.

The Toyoha mine is situated 40 kilometers southwest of Sapporo city, West Hokkaido, Japan. The mine is a hydrothermally active, polymetallic mineralized vein (Ohta, 1991) and well-known as one of most abundant indium mines in the world (Ohta, 1989; Ohta et al., 1998). It is also a rare geothermal site where not only sedimentary interstitial water but also magmatic water contributes to hydrothermal artesian spring water. The Toyoha deposit is at a very young age of mineralization, which have been formed 0.5-3 million years ago. The rock temperature is very high due to current geothermal activities (Urabe et al., 2001; Marumo, 2001; Mori et al., 2001, 2002).

One of our objectives is to survey biological activities in terrestrial subterranean hydrothermal environments in Toyoha mine. Besides, we aimed to evaluate hydrothermal stress on decomposition and racemization of amino acids in such extreme environments. Hydrothermal water and boring core samples were analyzed 
Takano et al., Organic Geochemistry, 34, 1491-1496 (2003).

for concentrations of total hydrolyzed amino acids (THAA) and their enantiomeric

50 ratio. The concentrations of amino acids were determined by ion-exchange liquid chromatography (IE-HPLC), and D/L ratios of amino acids were measured by reversed-phase high performance liquid chromatography (RP-HPLC).

\section{EXPERIMENTAL}

55 Samples

The hydrothermal water and boring core samples used were obtained in the Archaean Park Project (Marumo, 2001). Hydrothermal water samples welling from the cracks were collected at three locations (referred to as A, B, C-site, respectively) of $550 \mathrm{~m}$ below the land surface in a pit of Toyoha Mines, Hokkaido, Japan. The

60 highest temperature and $\mathrm{pH}$ of the hydrothermal water observed at the B-site were $71^{\circ} \mathrm{C}$ and 5.8, respectively (Mori et al., 2002). The water seeped from the wall at the rate of $2.0 \mathrm{l} / \mathrm{min}$. Two boring core samples (SN-101 and Toyoha 61) were analyzed: SN-101 was pyrite rich, and Toyoha 61 was quartz rich. The sample profile of geochemical aspect and biological survey have been preliminarily reported (Urabe et al., 2001; Kakegawa, 2001; Kuwabara et al., 2001; Mori et al., 2001, 2002).

\section{Pre-treatment of water samples}

An aliquot of the water sample were freeze-dried in test tubes which had been cleaned by soaking in $7 \mathrm{M} \mathrm{HNO}_{3}$ over night and rinsed with pure water. Six molar

$70 \mathrm{HCl}$ was added to the test tube. The test tube was sealed and at $110{ }^{\circ} \mathrm{C}$ in a block heater for 24 hours to obtain hydrolyzed amino acids. After evaporation to dryness, 
Takano et al., Organic Geochemistry, 34, 1491-1496 (2003).

the hydrolysates were dissolved in water, adjusted to $\mathrm{pH} \mathrm{1,} \mathrm{and} \mathrm{applied} \mathrm{to} \mathrm{a} \mathrm{Bio-Rad}$ AG-50W-X8 cation-exchange resin column (200-400 mesh) for desalting. Before application of the sample, the resin had been washed by passing $1 \mathrm{M} \mathrm{HCl}, \mathrm{H}_{2} \mathrm{O}, 1 \mathrm{M}$

$75 \mathrm{NaOH}$ and $\mathrm{H}_{2} \mathrm{O}$, successively. The resin was reactivated with $1 \mathrm{M} \mathrm{HCl}$ and rinsed with $\mathrm{H}_{2} \mathrm{O}$ just before applying the sample. The amino acid fraction was eluted from the column with $10 \% \mathrm{NH}_{3}$ aqueous solution. The elute was freeze-dried and re-dissolved in $0.1 \mathrm{M} \mathrm{HCl}$ before amino acid analysis. To compare with blank level of amino acids during laboratory handling, blank analysis by using same 80 ion-exchanged water, glass wares, HPLC, and RP-HPLC systems were performed.

\section{Pre-treatment of rock samples}

Rock core samples were carefully obtained and quickly sealed with dehydrating and deoxygenation agent package (AGELESS, Mitsubishi Gas Chemicals Co.).

85 Interior portion of five hundred mg each of the freeze-dried rock samples were ground. In order to eliminate external contamination, sample vials were sealed by thin membrane filter (MILLI WRAP, Millipore Co.) in prior to dryness. Then, it was digested with $5 \mathrm{ml}$ of $5 \mathrm{M} \mathrm{HF}-0.1 \mathrm{M} \mathrm{HCl}$ mixture in a sealed Teflon vessel at $110{ }^{\circ} \mathrm{C}$ for $16 \mathrm{~h}$. Then the mixtures were evaporated to dryness on a hot plate placed in a

90 draft chamber. The organic residues were dissolved in pure water while applying ultrasonic waves. The aqueous solutions were filtered through GF/A glass filters, and then freeze-dried in test tubes. They were hydrolyzed in sealed test tubes with $6 \mathrm{M}$ $\mathrm{HCl}$ at $110{ }^{\circ} \mathrm{C}$ for 2 hours. The hydrolysates were evaporated to dryness, and then desalted with AG-50W-X8 as previously described. Blank run was also performed 
Takano et al., Organic Geochemistry, 34, 1491-1496 (2003).

together with experimental samples.

\section{Determination of total hydrolyzed amino acids (THAA)}

The concentration of THAA was determined by ion-exchanged HPLC, which was composed of two high performance liquid chromatograph pumps (Shimadzu LC-6A), a cation-exchange column (Shimpak ISC-07/S1504, $4 \mathrm{~mm}$ i.d. $\times 150 \mathrm{~mm}$ ), a post column derivatization system, and a Shimadzu RF-535 fluorometric detector (Takano et al, 2001a). The derivatized reagents used were $\mathrm{N}$-acetyl-L-cystein and $o$ phthalaldehyde (OPA) in borate buffer. Sodium hypochlorite solution was used as the second derivatization reagent for the detection of imino acids such as proline.

105

\section{Measurement of enantiomeric ratio of amino acids}

Separation of D- and L-amino acid enantiomers was achieved by a reversed-phase (RP) HPLC system, which was composed of a high performance liquid chromatograph pumps (TOSOH CCPM II), a reversed-phase column (YMC-pack Pro C18 4.6 mm i.d.

$110 \times 250 \mathrm{~mm}$ ), and a TOSOH FS fluorometric 8020 detector (Excited wavelength: 355 $\mathrm{nm}$ and Emission wavelength: $435 \mathrm{~nm}$ ). Gradient elution was applied by using the following eluents; A: $40 \mathrm{mM}$ Sodium acetic acid buffer (pH 6.5), B: $100 \%$ methanol which was ultra-pure HPLC grade. Aliquot of the pre-treated sample was mixed well with OPA and N-acetyl-L-cystein in a glass vial. Then the mixture was passed

115 through a solid phase extraction column (TOYOPACK-ODS) to eliminate hydrophobic compounds. The eluent was injected to the RP-HPLC system. Gradient elution was applied using the following eluents; A: $40 \mathrm{mM}$ sodium acetic acid buffer (pH 6.5), B: 
Takano et al., Organic Geochemistry, 34, 1491-1496 (2003).

$100 \%$ methanol (ultra-pure HPLC grade). Gradient program was performed as follows: 10 min (Eluent B: 0 \%) - 25 min (Eluent B: $10 \%$ ) - 65 min (Eluent B: $20 \%$ ) $120-80 \min ($ Eluent B: $20 \%)-85 \min ($ Eluent B: $40 \%$ ) - $115 \min ($ Eluent B: $60 \%$ ) 120 min (Eluent B: $80 \%)-135$ min (Eluent B: $0 \%$ ).

All the glass wares were heated in a high temperature oven (Yamato DR-22) at 500 ${ }^{\circ} \mathrm{C}$ in prior to use in order to eliminate any possible contaminants. Water used was purified with a Milli-Q Labo and a Simpli Lab-UV (both Millipore Corporation) 125 successively.

\section{RESULT AND DISCUSSION}

Amino acids in hydrothermal water samples

Figure 1 shows typical chromatograms of amino acids in hydrothermal water sample

130 at the A-site and the B-site. Concentrations of amino acids in the hydrothermal water samples were summarized in Table 1. Glycine was the most abundant amino acid, and its concentration was ranged between $0.7-1.8 \mathrm{nmol} / \mathrm{ml}$. Other major amino acids were among proteinous amino acids. Non-proteinous amino acids such as $\beta$-alanine, $\gamma$-aminobutyric were also detected as minor constituents. Blank analysis of

135 amino acids during laboratory handling gave trace level amount of glycine (Takano et al., 2001b), which was less than ca. $10 \mathrm{pmol} / \mathrm{ml}$. Consequently determination of amino acids here were derived from hydrothermal water samples in Toyoha mine.

Since the pioneering work of Miller (Miller, 1953), numerous experimental studies have been carried out concerning the formation of biologically interesting organic 140 compounds simulated prebiotic conditions. Among these, amino acids could be 
Takano et al., Organic Geochemistry, 34, 1491-1496 (2003).

synthesized by hydrothermal abiotic processes such as laboratory experiment based on chemical evolution scenario (e.g. Yanagawa and Kobayashi, 1992; Islam et al., 2001). If the products of amino acids were abiotically formed, $\mathrm{D} / \mathrm{L}$ ratio will converge nearly 1.0 (Yanagawa and Kobayashi, 1992). On the other hand, amino acids associated

145 with life especially those form proteins are only L-form. Hence low D/L ratios seem to be good evidence of biological activities. As shown in Table 2, the D/L ratios of aspartic acid, glutamic acid and alanine showed that only slight racemization from L-form to D-form occurred. It was reported that thermodesulfovibrio and Acetobacterium were detected in hydrothermal vein at a depth of $550 \mathrm{~m}$, Toyoha mine

150 (Mori et al., 2002). As to biological population, microbial community analysis of subsurface hydrothermal water there were shown that microscopic observation indicated large population of subterranean microbe of $c a .10^{5}$ cell $/ \mathrm{ml}$ in hydrothermal water (Higashi and Maruyama, 2001). There is another organic source in hydrothermal water samples except microbial contents, that is, suspended particulate organic matter (POM) (e.g. Margaret et al., 2003) and dissolved organic matter (DOM) (e.g. David, 2001). POM and DOM contains multiple organics such as microbial corpse, hydrothermal altered peptides, sugars, nucleic acid bases and other wide variety of organic compounds. Number of organics in POM and DOM might be altered in some processes (e.g. Ratcliff et al., 1975) such as decarboxylation and 160 deamination under hydrothermal condition, resulting formation of secondary products. At the early stage of proteinous diagenesis or thermal alteration in terrestrial environment, the degradation of polypeptides, oligopeptides to amino acid monomers might be occurred (Ogasawara et al., 2001). Hence it is difficult to mention the 
Takano et al., Organic Geochemistry, 34, 1491-1496 (2003).

consistency with amino acid species and bacterial or archaean origins. The deep

165 subsurface is one of the major habitats for microorganisms (Gold, 1992). Indeed, procaryotic activities have been reported in environment at $120{ }^{\circ} \mathrm{C}$ or possibly even higher (Cragg et al., 1994). Those microbiological activities might contribute the production of organic compounds including amino acids under anaerobic environment and at high temperature in subterranean environments at Toyoha mine.

\section{Amino acids in rock samples}

Concentration of amino acids in the interior portion of rock samples were shown in Table 3. SN-101 was sulfur containing pyrite rich vein, but amino acids with sulfur such as methionine were not detected. Relative abundance of dicarboxylic amino

175 acids such as aspartic acid and glutamic acid, and that of amino acids with hydroxylic group such as serine and threonine in the rock samples were much more than those in the hydrothermal water samples. Hydrothermal stress may cause decomposition of amino acid via decarboxylation (Ratcliff et al., 1974), i.e., aspartic acid will alter to $\beta$-alanine by decarboxylation at $\alpha$-carbon (Schroeder, 1975; Cowie and Hedges, 1994).

180 An interesting characterization of the ratio of $\beta$-ala/Asp in these samples were extracted: ratios of $\beta$-ala/Asp show $0.14,0.15$, and 0.20 in hydrothermal water sample $\mathrm{A}, \mathrm{B}$, and $\mathrm{C}$, respectively. $\quad$ On the other hand, ratios of $\beta$-ala/Asp show 0.01 and 0.02 in rock sample $\mathrm{SN}-101$ and 61 , respectively. The minor constituent of $\beta$-alanine in rock samples are crucial that amino acids in interior rock seem to be more stable than dissolved in hydrothermal water.

Figure 2 shows a reversed-phase chromatogram of amino acid enantiomers in the 
Takano et al., Organic Geochemistry, 34, 1491-1496 (2003).

core sample $\mathrm{SN}-101$. The process of amino acid racemizaion occurring in various geochemical samples in terrestrial and marine environments has been widely applied in geochemical research (e.g. Harada and Handa, 1995). Racemization of amino acids is primarily dependent on the age and temperature of the environment (Bada and Schroeder, 1975). The hydrothermal process may progress in kinetic control with environmental temperature (Bada, 1972), therefore, $\mathrm{D} / \mathrm{L}$ ratios were determined and used as indicators of the extent of organic matter alteration and coincidence of subterranean microbial activities. Racemization rate constant was reported to be higher in hot geothermal condition (Bada, 1972), although, the observed D/L ratio of amino acids in the core samples may imply anaerobic microbiological activities as well as hydrothermal water samples. Since the temperature increases with depth, it has been suggested that hyperthermophiles, in particular chemiolithoautotrophs, are abundant in subterranean environments forming a deep hot biosphere (Gold, 1992).

200 Possible existence of anaerobic subsurface lithoautotrophic microbial systems has been reported (Stevens, 1995). The present results showed the possibility of subterranean microbial activities in Toyoha mine. Additionally, isolation of a new thermophilic, strictly anaerobic, thiosulfate-reducing bacteria in hydrothermal vent at Toyoha mine gave an implication of the presence of deep subterranean microbial activities.

\section{CONCLUSION}

Total concentration of amino acids in the hydrothermal water ranged from 2.6 to $6.1 \mu \mathrm{mol} / 1$, and that of the hydrothermal vein rocks was from 87 to $230 \mathrm{nmol} / \mathrm{g}$-rock. Relative abundance of acidic amino acids such as aspartic acid and glutamic acid in the 
Takano et al., Organic Geochemistry, 34, 1491-1496 (2003).

210 hydrothermal waters was lower than that in the hydrothermal vein rocks. The $\mathrm{D} / \mathrm{L}$ ratios of the samples implied the presence of subterranean microbiological activities, rather than the contribution of abiotic hydrothermal synthesis of amino acids.

It is widely believed that the hydrothermal systems in deep ocean have played important roles for the emergence of life under the primitive earth conditions (e.g.

215 Holm, 1992; Yanagawa et al, 1988, 1992; Islam et al., 2001). From the point of view of chemical evolution and origins of life, it is of interest that distribution and stereo chemistry of amino acids in submarine hydrothermal sub-vent systems will have to be clarified (Takano et al., 2001b). In order to build up a consolidated model of extreme environmental geology, biology and chemistry in submarine hydrothermal vent, an integral research project on interaction between sub-vent biosphere, "Archaean Park Project" which is called, is now in progress (Urabe et al., 2001).

Acknowledgement- The authors express their sincere thanks to Mark A. Altabet, School for Marine Science and Technology, University of Massachusetts for numerous 225 comments which helped to improve the manuscript. The authors would like to thank Dr. K. Mori, National Institute for Advanced Industrial Science and Technology, for giving water samples. They are indebted to Dr. H. Naraoka, Department of Chemistry, Tokyo Metropolitan University and Dr. Y. Kawasaki, Mitsubishi Kagaku Institute of Life Science, for providing us with the helpful suggestions.

230 This work was funded by MEXT (Ministry of Education, Culture, Sports, Science and Technology, Japan) through “Archaean Park Project (International research project on interaction between sub-vent biosphere and geo-environment)". 
Takano et al., Organic Geochemistry, 34, 1491-1496 (2003).

\section{REFERENCES}

Bada, L. J., 1972. Kinetics of racemization of amino acids as a function of pH. J. Ame. Chem. Soc., 94, 1371-1373.

Bada, J. L. and Schroeder, R. A. 1975. Amino acid racemization reactions and their geochemical implications. Naturwissenschaften 62, 71-79.

240 Cowie, G. L., Hedges, J. I. 1994. Biochemical indicators of diagenetic alteration in natural organic matter mixtures. Nature, 369, 304-307.

Cragg, B. A., Parkes, R. J., 1994. Bacterial profiles in hydrothermally active deep sediment layers from Middle Valley (N.E.Pacific) Site 857 and 858. Proc.Ocean Drilling Prog. Sci. Result, 1994, 139, 509-516.

245 David, J. B., 2001. Dissolved organic matter in Chesapeake Bay sediment pore waters, Org. Geochem., 32, 487-505.

Gold, T., 1992. The deep, hot biosphere. Proc. Natl. Acad. Sci. USA, 89, 6045-6049.

Harada, N. and Handa, N. 1995. Amino acid chronology in the fossil planktonic foraminifera, Pulleniatina obliquiloculata from Pacific Ocean. Geophys. Res. Lett. 22, 2353-2356.

Higashi, Y. and Maruyama, A. 2001. Microbial community analysis of subsurface hydrothermal environments in Toyoha mine, Hokkaido, Japan. Japan Earth and Planetary Science Joint Meeting, Cm-013.

Holm, N. G., (Ed.). 1992. Marine hydrothermal systems and the origin of life- ${ }^{-}$special issue, Origins Life Evol. Biosphere, 22, 1-191. 
Takano et al., Organic Geochemistry, 34, 1491-1496 (2003).

Islam, M. N., Kaneko, T., Kobayashi, K. 2001. Determination of amino acids formed in a supercritical water flow reactor simulating submarine hydrothermal systems. Analytical Science, 17, 1631-1634.

Kakegawa, T., 2001. Biological and non-biological sulfide precipitation from hydrothermal fluids at the Toyoha Mine, Hokkaido. Japan Earth and Planetary Science Joint Meeting, Cm-011.

Kuwabara, T., Saida, H., Utsumi, M. 2001. Microorganisms and microbial activities in hydrothermal systems in the Toyoha mine. Japan Earth and Planetary Science Joint Meeting, Cm-P007.

265 Margaret, G. B., Kurt, R. B., Francisco, P. C., Simon, C. B., 2003. Seasonal variation in alkenones, bulk suspended POM, plankton and temperature in Monterey Bay, California: implications for carbon cycling and climate assessment. Org. Geochem., 34, 837-855.

Marumo, K., 2001. AP project drilling at the Toyoha $\mathrm{Pb}-\mathrm{Zn}-\mathrm{Cu}-\mathrm{Ag}$ hydrothermal deposite, Hokkaido. Japan Earth and Planetary Science Joint Meeting, Cm-010.

Miller,S. L., 1953. Production of amino acids under possible primitive earth condition. Science, 117, 528-529.

Mori, K., Hanada, S., Maruyama, A., 2001. Thermophilic anaerobic microorganisms isolated from a thermal vein in Toyoha mine. Japan Earth and Planetary Science Joint Meeting, Cm-P008.

Mori, K., Hanada, S., Maruyama, A., Marumo, K. 2002. Thermanaeromonas toyohensis gen. nov., sp. nov., a novel thrmophilic anaerobe isolated from a subterranean vein in Toyoha Mines. Int. J. Systematic Evol. Microbiol., 52, 1675-1680. 
Takano et al., Organic Geochemistry, 34, 1491-1496 (2003).

Ogasawara, O., Ishiwatari, R. and Shimoyama, A. 2001. Detection of water extractable dipeptidesand their characteristics in recent sediment of Tokyo Bay. Geochem. J., 35, 439-450.

Ohta, E., 1989. Occurrence and chemistry of indium-containing minerals from the Toyoha mine, Hokkaido, Japan. Mining Geol., 39, 355-372.

285 Ohta, E., 1991. Polymetallic mineralization at the Toyoha mine, Hokkaido, Japan. Mining Geol.,41, 279-295.

Ohta, E., Kawano, Y., Nakagawa, M., Kagami, H., 1998. Petrochemistry of late Miocene to Quaternary igneous rocks and metallogenesis in southwest Hokkaido, Japan. Resource Geol., 48, 183-195.

290 Parkes, R. J., Cragg, B. A., Bale, S. K., Getliff, J. M., Goodman, K., Rochelle, P. A., Fry, J. C., Weightman, A. J., Harvey, S. M. 1994, Deep bacterial biosphere in Pacific ocean sediments. Nature, 371, 410-413.

Ratcliff, M. A., Jr., Medley, E. E., Simmonds, P.G., 1974. Pyrolysis of amino acids. Mechanistic Considerations. J. Org. Chem., 39, 1481-149.

295 Schroeder, R. A., 1975. Absence of $\beta$-alanine and $\gamma$-aminobutyric in cleaned foraminiferal shells: Implications for use as a chemical criterion to indicate removal of non-indigenous amino acid contaminants. Earth Planet.Sci.Lett., 25, 274-278.

Stevens, T. O., MaKinley, J. P., 1995. Lithoautotrophic microbial ecosystems in deep basalt aquifers. Science, 270, 450-454.

Takano, Y., Masuda, H., Ushio, K., Kaneko, T., Kobayashi, K., Saito, T., 2001a. Determination of organic compounds formed in simulated interstellar dust 
Takano et al., Organic Geochemistry, 34, 1491-1496 (2003).

environment. Analytical Science, 17, 1635-1638.

Takano, Y., Kobayashi, K., 2001b. D/L ratio of amino acids in terrestrial core sample 305 and microbial activities. Japan Earth and Planetary Science Joint Meeting, Cm-P004.

Urabe, T., Sheama, N., Ishibashi, J., Maruyama, A., Marumo, K., 2001. On the Archaean Park Project; International Research Project on interaction between sub-vent biosphere and geo-environment. Japan Earth and Planetary Science Joint $310 \quad$ Meeting, Cm-001.

Yanagawa, H., Kobayashi, K., 1992. An experimental approach chemical evolution in submarine hydrothermal systems. Origins Life Evol. Biosphere, 22, 147-159. 
Takano et al., Organic Geochemistry, 34, 1491-1496 (2003).

\section{Figure and Table caption}

Fig.1 Ion-exchange chromatograms of hydrolyzed amino acids in the hydrothermal

315 water sample of A-site sample. Abbreviations. Asp:aspartic acid, Ser: serine, Glu: glutamic acid, Pro: Proline, Gly: glycine, Ala: alanine, Val: valine, Met: Methionine, Ile: isoleucine, Leu: leucine, Tyr: tyrosine, Phe: phenylalanine, $\beta$-Ala: $\beta$-alanine, $\gamma$-ABA: $\gamma$-aminobutyric acid, $\delta$-AVA: $\delta$-aminovaleric acid.

320 Fig. 2 Reversed-phase chromatogram of amino acid enantiomers in the core sample SN-101. Abbreviations for amino acids: D, L-Asp: D, L-aspartic acid, Ser: serine, D, L-Glu: D, L-glutamic acid, D, L-Ala: D,L-alanine, $\beta$-Ala: $\beta$-Alanine. $\quad$ - and L- serine peaks are not separated.

325 Table 1 Concentration of amino acids in the hydrothermal water at Toyoha mine, Hokkaido, Japan.

Table $2 \mathrm{D} / \mathrm{L}$ ratios of aspartic acid, glutamic acid and alanine in hydrothermal water and core samples in Toyoha mine, Hokkaido, Japan.

Table 3 Concentration of amino acids in the core samples at Toyoha mine, Hokkaido, Japan. 
Figure 1

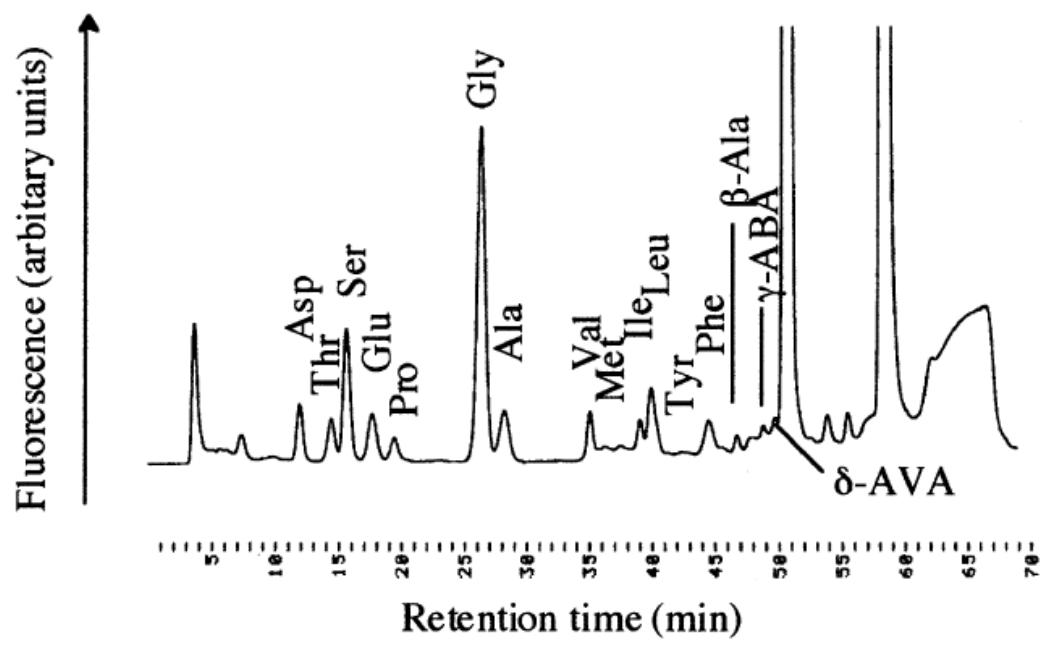

Figure 2

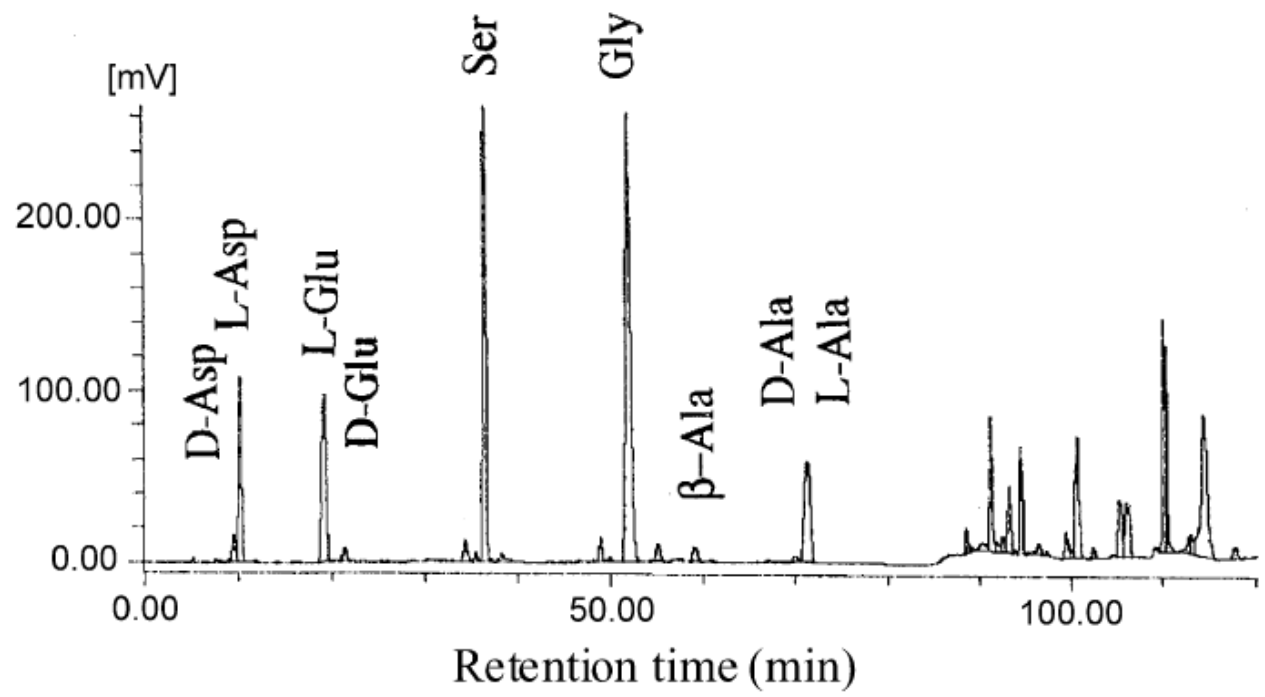


Table 1

\begin{tabular}{|c|c|c|c|c|c|c|}
\hline \multirow[b]{2}{*}{ Sampling site } & \multicolumn{3}{|c|}{ concentration } & \multicolumn{3}{|c|}{ mole ratio } \\
\hline & A-site & B-site & C-site & A-site & B-site & $\mathrm{C}$-site \\
\hline temperature* $/{ }^{\circ} \mathrm{C}$ & 63.5 & 71.3 & 48.3 & - & - & - \\
\hline $\mathrm{pH}^{*}$ & 6.6 & 5.8 & 6.6 & - & - & - \\
\hline unit & \multicolumn{3}{|c|}{$\mu \mathrm{mol} / 1$} & \multicolumn{3}{|c|}{$\%$ mole } \\
\hline Asp & 0.36 & 0.26 & 0.30 & 5.93 & 10.30 & 11.60 \\
\hline Thr & 0.24 & 0.14 & 0.13 & 3.92 & 3.03 & 5.00 \\
\hline Ser & 0.75 & 0.38 & 0.38 & 12.37 & 8.23 & 14.74 \\
\hline Glu & 0.19 & 0.13 & 0.20 & 3.18 & 2.80 & 7.60 \\
\hline$\alpha$-AAA & n.d. & n.d. & n.d. & - & - & - \\
\hline Gly & 1.78 & 1.45 & 0.70 & 29.20 & 31.61 & 27.24 \\
\hline Ala & 0.47 & 0.28 & 0.21 & 7.69 & 6.00 & 8.32 \\
\hline$\alpha-\mathrm{ABA}$ & n.d. & n.d. & n.d. & - & - & - \\
\hline Val & 0.38 & 0.20 & 0.28 & 6.18 & 4.33 & 10.74 \\
\hline Cys & 0.09 & 0.68 & n.d. & 1.47 & 14.84 & - \\
\hline Met & 0.22 & 0.17 & $\operatorname{tr}$ & 3.66 & 3.70 & - \\
\hline Ile & 0.23 & 0.14 & 0.03 & 3.74 & 3.06 & 1.12 \\
\hline Leu & 0.71 & 0.44 & 0.10 & 11.59 & 9.54 & 3.81 \\
\hline Tyr & tr. & n.d. & tr. & - & - & - \\
\hline Phe & 0.33 & 0.19 & 0.07 & 5.37 & 4.16 & 2.86 \\
\hline$\beta$-Ala & 0.05 & 0.04 & 0.06 & 0.77 & 0.81 & 2.21 \\
\hline$\beta-\mathrm{AiBA}$ & n.d. & n.d. & n.d. & - & - & - \\
\hline$\gamma$-ABA & 0.14 & 0.02 & tr. & 2.34 & 0.54 & - \\
\hline$\delta$-AVA & tr. & tr. & n.d. & - & - & - \\
\hline Pro & 0.16 & 0.11 & 0.12 & 2.54 & 2.49 & 4.71 \\
\hline Total & 6.10 & 4.60 & 2.57 & 100 & 100 & 100 \\
\hline
\end{tabular}

tr.: trace amount (detected but not quantified.), n.d.: not detected * Mori et al., 2002.

Table 2

\begin{tabular}{ccccccc}
\hline \hline & \multicolumn{3}{c}{ hydrothermal water } & & \multicolumn{2}{c}{ core } \\
\cline { 2 - 3 } \cline { 5 - 6 } Sample & A-site & B-site & C-site & & SN101-14 & 61 \\
\cline { 6 - 7 } Asp & 0.08 & 0.05 & 0.15 & & 0.13 & 0.06 \\
Glu & 0.09 & 0.16 & 0.09 & & 0.06 & 0.09 \\
Ala & 0.06 & 0.00 & 0.00 & & 0.05 & 0.05 \\
\hline \hline
\end{tabular}


Table 3

\begin{tabular}{|c|c|c|c|c|}
\hline \multirow[b]{2}{*}{ core } & \multicolumn{2}{|c|}{ concentration } & \multicolumn{2}{|c|}{ mole ratio } \\
\hline & SN101-14 & 61 & SN101-14 & 61 \\
\hline unit & \multicolumn{2}{|c|}{$\mathrm{nmol} / \mathrm{g}$-rock } & \multicolumn{2}{|c|}{$\%$ mole } \\
\hline Asp & 21.45 & 7.86 & 9.32 & 9.04 \\
\hline Thr & 11.15 & 3.94 & 4.85 & 4.54 \\
\hline Ser & 56.64 & 17.28 & 24.63 & 19.88 \\
\hline Glu & 20.42 & 4.90 & 8.88 & 5.64 \\
\hline$\alpha$-AAA & n.d. & n.d. & - & - \\
\hline Gly & 61.37 & 23.99 & 26.68 & 27.60 \\
\hline Ala & 25.22 & 9.28 & 10.96 & 10.68 \\
\hline$\alpha-\mathrm{ABA}$ & n.d. & n.d. & - & - \\
\hline Val & 9.19 & 4.50 & 4.00 & 5.18 \\
\hline Cys & n.d. & n.d. & - & - \\
\hline Met & n.d. & n.d. & - & - \\
\hline Ile & 4.42 & 2.09 & 1.92 & 2.40 \\
\hline Leu & 7.32 & 4.58 & 3.18 & 5.27 \\
\hline Tyr & 0.54 & tr. & 0.24 & - \\
\hline Phe & 2.93 & 3.55 & 1.27 & 4.09 \\
\hline$\beta$-Ala & 0.35 & 0.20 & 0.15 & 0.24 \\
\hline$\beta$-AiBA & n.d. & n.d. & - & - \\
\hline$\gamma-\mathrm{ABA}$ & 0.50 & 0.32 & 0.22 & 0.36 \\
\hline$\delta$-AVA & tr. & n.d. & - & - \\
\hline Pro & 9.78 & 4.43 & 4.25 & 5.10 \\
\hline Total & 230.00 & 86.93 & 100 & 100 \\
\hline
\end{tabular}

tr.: trace amount (detected but not quantified.), n.d.: not detected 